\title{
Body Quest Parent: A Text Message Parent Education Intervention to Supplement a School-Based Obesity Prevention Initiative for Third-Graders
}

\author{
Katie Funderburk, MS, RD ${ }^{1}$; Barb Struempler, PhD $^{1,2}$; Sondra M. Parmer, PhD ${ }^{1}$; \\ Jamie B. Griffin, PhD, RDN, LDN ${ }^{1,2}$
}

\section{INTRODUCTION}

School-based nutrition interventions can be a tool for encouraging parents to improve home food environments. However, interventions should address barriers to receiving and applying nutrition education such as time, money, transportation, preferences of family members, and limited cooking skills. ${ }^{1}$ Text-based education may address these barriers. Research shows that 91\% of American adults are cell phone owners and $78 \%$ of lower-income cell phone owners send and receive texts. ${ }^{2}$

\section{PROGRAM DEVELOPMENT AND IMPLEMENTATION}

Body Quest (BQ) ${ }^{3}$ is an Alabama Extension obesity prevention program for third-graders in Supplemental Nutrition Assistance Program-Education (SNAP-Ed)-eligible schools. To supplement BQ, Alabama Extension also developed Body Quest Parent (BQP), a text message-based nutrition education intervention for parents designed to decrease barriers to traditional education methods. In addition to receiving texts, parents acted as recipe testers in a model that increased vegetable consumption in an adult SNAPEd population. ${ }^{4}$ The goal of this study was to determine the effectiveness of BQP to improve the home food environment related to (1) vegetable accessibility, (2) parental modeling of vegetable consumption, and (3) preparation of vegetable-rich recipes. The Auburn University Institutional Review Board approved this study.

In fall, 2014, parents $(n=3,567)$ of BQ students consented to participate in BQP simultaneously. Parents were $93 \%$ female, $40 \%$ were black and $60 \%$ were white, and $70 \%$ had a high school education or less. Extension educators read standardized recruitment scripts to students explaining the parent initiative and sent home consent forms for parents to sign and return. Parents were asked to provide a cell phone number to receive text messages and participate in phone surveys; $95 \%$ of consenting parents $(n=3,398)$ provided a cell phone number.

Text messages containing educational tips and action prompts were sent via short message service marketing software. During the 15-week intervention, parents received 3 weekly

\footnotetext{
${ }^{1}$ Alabama Cooperative Extension System and Supplemental Nutrition Assistance Program Education, Auburn University, Auburn, AL

${ }^{2}$ Department of Nutrition, Dietetics and Hospitality Management, Auburn University, Auburn, $\mathrm{AL}$

Conflict of Interest Disclosure: The authors' conflict of interest disclosures can be found online with this article on www.jneb.org.

Address for correspondence: Katie Funderburk, MS, RD, Auburn University, 206 Duncan Hall, Auburn, AL 36849; Phone: (334) 734-3149; Fax: (334) 844-2252; E-mail: kem0017@auburn.edu.

J Nutr Educ Behav. 2018;50:415-417

(C) 2018 The Author(s). Published by Elsevier, Inc. on behalf of the Society for Nutrition Education and Behavior. This is an open access article under the CC BY-NC-ND license (http://creativecommons.org/licenses/by-nc-nd/4.0/).

https://doi.org/10.1016/j.jneb.2018.01.007
}

Journal of Nutrition Education and Behavior • Volume 50, Number 4, 2018

texts, each of which targeted 1 of the 3 home food environment BQP goals. Every 2 weeks, Extension educators provided students with free recipe magnets featuring easy-to-prepare vegetables dishes to give to parents for home preparation (Figure 1). To encourage recipe preparation, texts included tips specific to vegetables featured in each recipe.

\section{EVALUATION AND RESULTS}

The researchers conducted 2 types of evaluation. First, a phone assessment was adapted for BQP from existing instruments measuring recipe preparation $^{4}$ and the home food environment. ${ }^{5}$ Before the start and at the conclusion of the intervention, phone interviews were conducted verbally in English by trained interviewers with a random sample of parents $(\mathrm{n}=794)$. Second, a texting poll was conducted with a randomly generated subsample of parents $(n=614)$ to gather descriptive information and feedback. There was a $22 \%$ response rate $(\mathrm{n}=135)$.

For the phone assessments, $t$ tests analyzed differences from preintervention to postintervention. Parents made 3 positive changes in the home environment. First, they significantly increased accessibility of vegetables in the home for thirdgraders by making vegetables easier to see, reach, and eat $(t=-2.67 ; P=.009)$. Second, parents significantly increased modeling of vegetable consumption by enjoying vegetables with their thirdgraders $(t=-3.10 ; P=.002)$. Third, parents prepared vegetable recipes at home throughout the intervention; over $54 \%$ of parents participating in phone surveys reported making all 6 recipes at home within 2 weeks of receiving them. Descriptive statistics of 


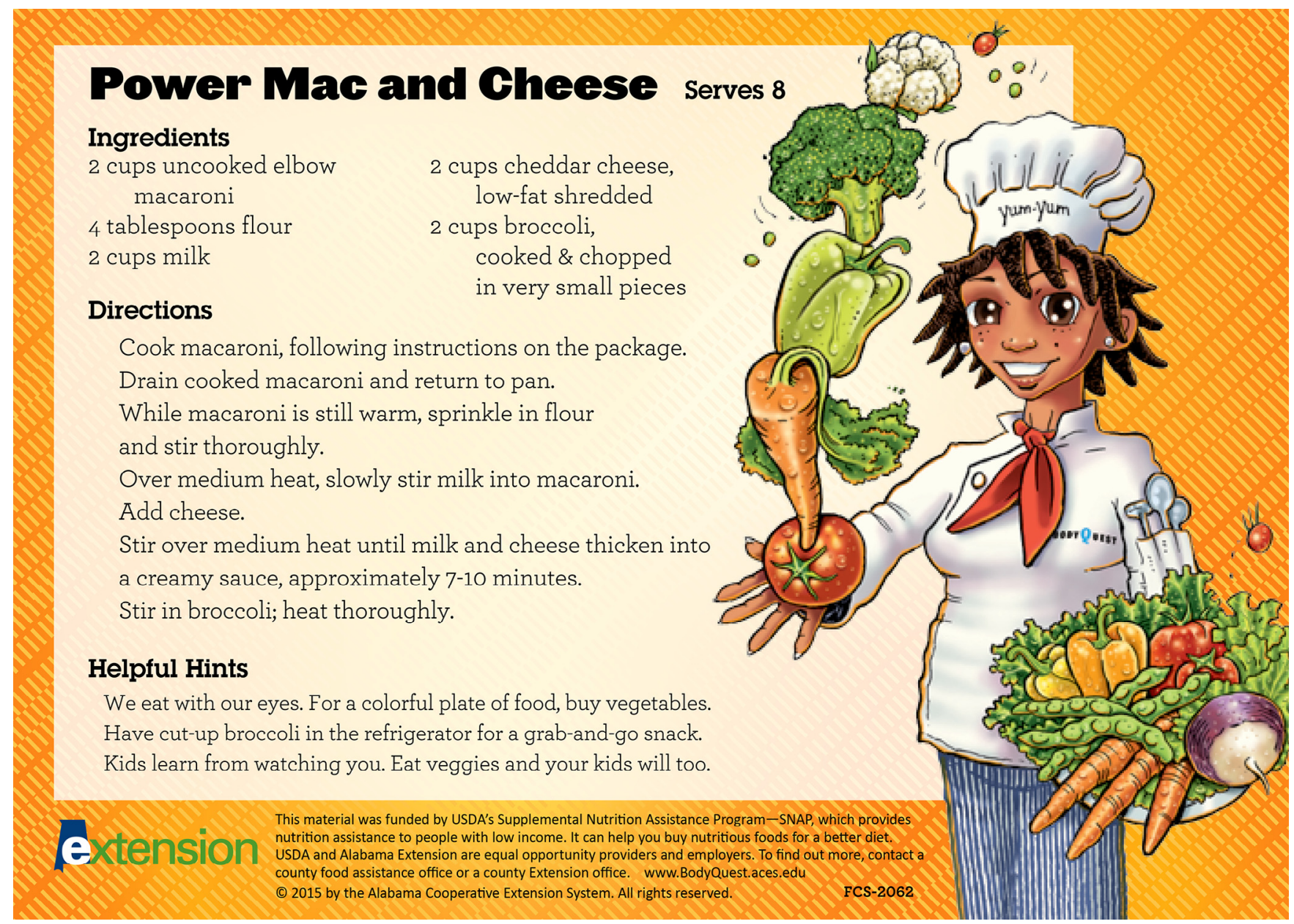

Figure 1. Recipes were printed on Body Quest-themed magnets and included nutrition tips.

texting poll results showed (1) satisfaction, through positive feedback; and (2) effectiveness, through selfreported positive behaviors related to vegetables, of the texting initiative within the sample (Figure 2). Parents could opt out of the texting program at any time, but $76 \%$ of enrollees chose

Figure 2. Text message poll responses showed the percentage of participants $(n=135)$ reporting positive experiences and behaviors after the texting initiative.

to continue receiving text messages for the entire intervention.

Limitations of this study included a small sample size for the texting poll that could not represent the whole sample accurately. There was also lack of follow-up to assess whether changes were sustained after 15 weeks. In addition, three fourths of parents did not respond to the texting poll for unknown reasons. Finally, measurements of vegetable intakes of parents and children were lacking.

Body Quest Parent encouraged parents to improve the home food environment through text messagebased education.

\section{ACKNOWLEDGMENTS}

Auburn University's Institutional Review Board approved this study. Artwork for $B Q P$ recipe magnets is available for free download at 
https://store.aces.edu/itemdetail. aspx?ProductID=18461. Body Quest Parent was funded by Alabama Extension and the US Department of Agriculture's SNAP-Ed. Appreciation is given to SNAP-Ed educators who helped implement BQP.

\section{REFERENCES}

1. Rolnick SJ, Calvi J, Heimendinger J, et al. Focus groups inform a web-based program to increase fruit and vegetable intake. Patient Educ Couns. 2009;77:314-318.

2. Duggan M. Cell phone activities 2013. Pew Research Center: Internet and Technology; September 19, 2013. http:// www.pewinternet.org/2013/09/19/cellphone-activities-2013/. Accessed May 23, 2017.

3. Struempler B, Parmer S, Mastropietro L. Changes in fruit and vegetable consumption of third grade students in Body Quest: Food of the Warrior, a 17-class childhood obesity prevention program. J Nutr Educ Behav. 2014;46:286-292.

4. Kim K, Struempler BJ, Parmer SM. Decision of SNAP recipients to consume more vegetables: an application of the Theory of Planned Behavior. J Hunger Environ Nutr. 2011;6:294-311.

5. Robinson-O'Brien R, Neumark-Sztainer D, Hannan PJ, Burgess-Shampoux T, Haines J. Fruits and vegetables at home: child and parent perceptions. J Nutr Educ Behav. 2009;42:360-364.

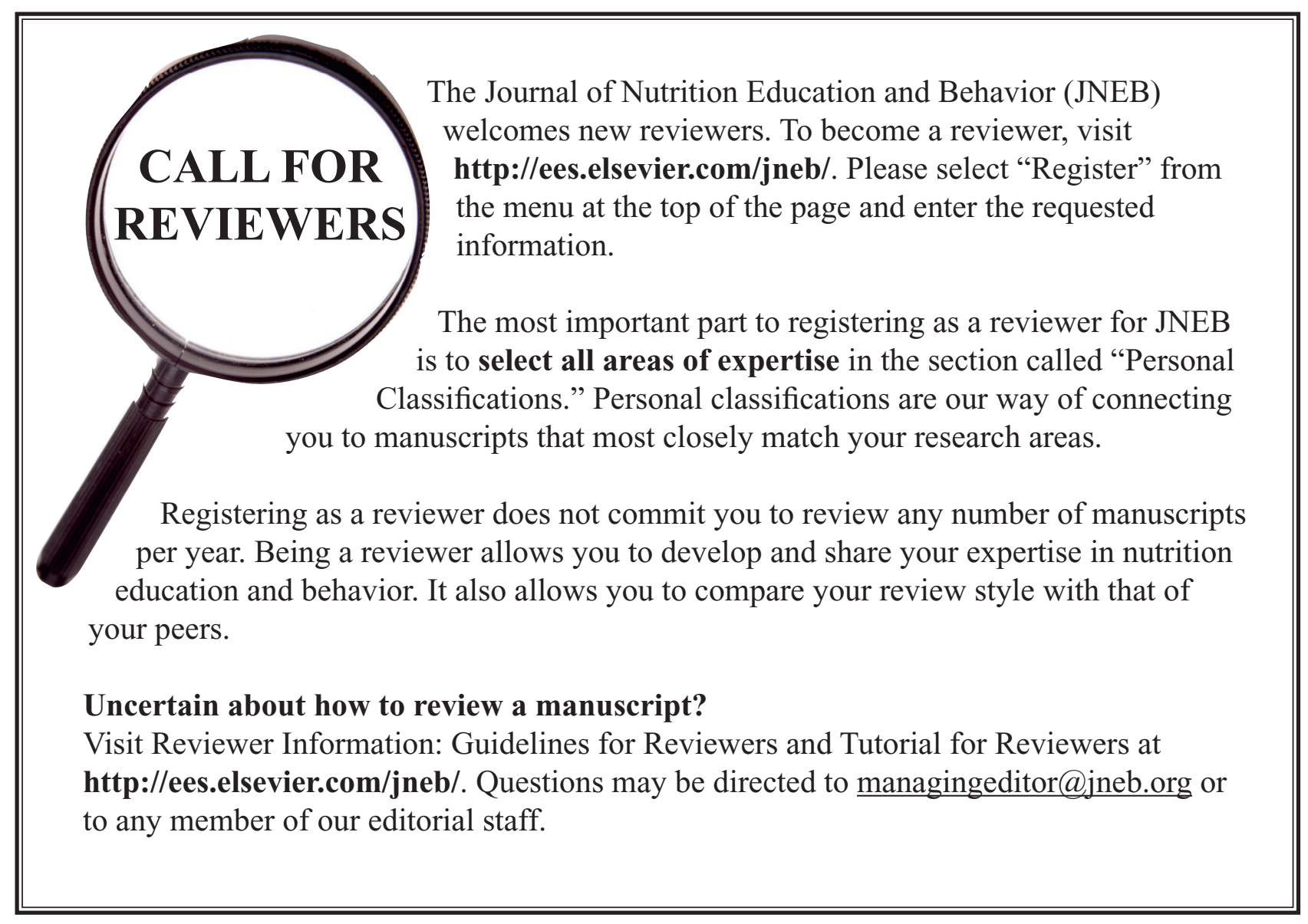


- Volume 50, Number 4, 2018

\section{CONFLICT OF INTEREST}

The authors have not stated any conflicts of interest. 